\title{
NOTICIAS TEATRALES PARA EL VIRREINATO DE NUEVA ESPAÑA DURANTE EL SIGLO XVI
}

Juan Collantes de Terán

En los setenta y ocho años en que se desenvuelve la dominación hispana en la capital del virreinato de Nueva España durante el siglo XVI, es decir, desde 1521 a 1599 , las representaciones teatrales ofrecen un variado muestrario escenográfico y se van acoplando paulatinamente a las vicisitudes políticas, religiosas y sociales que afectan a la ciudad. En Méjico, durante ese período, evoluciona un teatro misionero de carácter evangelizador que comienza en el ternplo para salir más tarde a las calles y plazas donde, convertido en espectáculo, será blanco de prohibiciones y censuras por parte de los cabildos eclesiástico y civil. Si importante es para un conocimiento cabal de la puesta en escena de estas primeras manifestaciones la adaptación por los misioneros franciscanos de temas bíblicos a la mentalidad de los indios, aprovechando los ciclos litúrgicos del año y otras fiestas religiosas importantes en el calendario religioso y civil de la ciudad, es también interesante comprobar cómo la edificación de los primeros templos se concibe, a veces, en función de tales representaciones; un buen ejemplo de ello son las Ilamadas «capillas abiertas» que comienzan a construirse alrededor de 1535 con una concepción arquitectónica determinada, donde el templo tiene, además de su funcionalidad religiosa, una misión claramente exhibidora de la liturgia adaptada a la mentalidad de los indios, quienes en sus antiguos ritos conocieron y desarrollaron una singular escenografía. Es lo que lleva a Antonio Magaña y Ruth S. Lamb a expresar lo siguiente: «En rigor, los franciscanos no hicieron más que aprovechar los escenarios a que ya estaban acostumbrados los indígenas y trasplantar las piezas religiosas con el propósito de difundir el nuevo credo. Frecuentemente ni siquiera la palabra era indispensable, al menos en las primeras representaciones, pues bastaba la pantomima de grande espectáculo para difundir su enseñanza» ${ }^{1}$.

1 Antonio Magaña Esquivel: Breve historia del teatro mexicano (México. Ediciones De Andrea. 1958), pág. 16. 
Tal vez está aquí planteado en síntesis lo que fue el desarrollo teatral en Méjico en los primeros años de la presencia peninsular en Nueva España. Una preocupación eminentemente religiosa que aprovecha las formas dramáticas que habían sido habituales en la población que contemplaba la representación. Así se explica, por ejemplo, en las narraciones de Fray Toribio de Benavente su preocupación por describir con todo lujo de detalles el escenario urbano que se preparaba para el cortejo eucarístico el día de la festividad del Corpus Christi. Liturgia y espectáculo debían, es indudable, hacer mella en el ánimo del pueblo que contemplaba con sorpresa y estupor y eran, además, dos cualidades indispensables en toda escenografía teatral ${ }^{2}$.

Así pues, los primeros destellos teatrales en Méjico marcan un tipo de representación que, aun al final del siglo, todavía se enfoca bajo el prisma religioso, cuando la ciudad para entonces posee casa propia para la representación de las comedias y se tengan documentos fidedignos para conocer la primeras compañías de cómicos, así como las escenificaciones y montajes de las obras. Desde las primeras noticias teatrales que tenemos en el territorio del virreinato, tales como el texto titulado Representación del Fin del Mundo, en Santiago de Tlaltelolco, tal vez la primera muestra del género en su matiz evangelizador en aquellas tierras, hasta las actuaciones del comediante Andrés Laris de Durango del que tenemos noticias en 1597 cuando pide al cabildo de la ciudad seiscientos pesos por representar Las profecías de Daniel y Nuestra Señora del Rosario, hay todo un proceso de desarrollo en el que no se pierde el carácter religioso que normalmente había tenido al inicio, es decir, desde 1524 cuando llegan los llamados «doce apóstoles») de la orden franciscana para encargarse del catecumenado de los indios mejicanos.

De tal forma es así que hoy se puede ver el panorama teatral en aquel virreinato durante el siglo XVI con mayor nitidez. Así podemos distinguir dos zonas de fechas que abarcarían también dos etapas bajo la influencia de los franciscanos, tal como se ha señalado, la primera y otra sobre la que incide la presencia de los jesuítas en la segunda; esto es, primero desde 1524 a 1572 y, después, desde esta fecha hasta final de siglo. La primera etapa la dividimos en dos épocas: hasta 1546 cuando termina el pontificado del arzobispo fray Juan de Zumárraga, franciscano también, con quien el teatro empieza a conocer las primeras prohibiciones y censuras; y la segunda etapa hasta la presencia de los religiosos de la Compañía de Jesús, una vez terminado el Concilio de Trento. Estas censuras, en todo caso, iban aligerando, como es lógico, el proceso de secularización que se opera en el teatro e intentaban separarlo de las fiestas litúrgicas propiamente dichas, como dice del Saz: «por estimarlas en el camino de la desvergüenza, porque, según datos de Joaquín García de Icazbalceta, entorpecían la labor eclesiástica haciendo estruendo, estorbando los cantos de la iglesia, representando profanos triun- 
fos, como el del dios Amor» ${ }^{3}$. Aun en 1585, en el Tercer Concilio Mexicano se renueva la prohibición de celebrar las representaciones dentro de los templos, tal como se hiciera en la época de Zumárraga.

Desde 1572 hasta el final de siglo se desarrolla en Méjico en las casas y colegios de los jesuítas unas elaboradas piezas, escritas en latin, en prosa y en verso, que recitaban los alumnos de aquellos centros. Estas representaciones, llamémoslas así, tenían unos rasgos característicos y propios: piezas de claro corte humanístico, académicas, con materiales europeos, en forma de diálogos alegóricos, recitadas en certámenes públicos y actos colegiales. Tenemos registradas actuaciones de este tipo hasta 1595, en que se pone en escena la recitación de una pieza con motivo de inaugurar el curso en el Colegio Máximo de San Padro y San Pablo, al que asiste el virrey, por entonces el Conde de Monterrey; se trata, como dice Magaña, de un coloquio «de varios metros latinos» ${ }^{4}$. Conocemos algunos nombres de autores de esta clase de certámenes, profesores de latinidad y retórica, de ahí que la mayor parte de estas obras fueran comedias clásicas que terminan con el siglo decayendo notablemente debido a sus propias limitaciones y quedan como simples ejercicios de escolares para la declamación, alternando el latín y el castellano.

Al comenzar la secularización del teatro en Méjico, poco más mediado el siglo XVI, empieza a vislumbrarse otro tipo de representación que, al principio no tiene un fin doctrinal, y sigue los esquemas de la comedia española al uso y, esto es lo importante, se escribe por autores mejicanos; se diría un teatro «criollo» que tiene gran sentido profesional; el pueblo ya no participa en la acción y comienza a buscar poco a poco un lugar estable donde desarrollar la representación. Los críticos e historiadores ${ }^{5}$ participan del criterio uniforme al asignar la «comedia pastoril», del presbítero Juan Pérez Rodríguez, titulada Desposorio Espiritual entre el Pastor Pedro y la Iglesia Mexicana, como la primera producción dramática del ingenio criollo en toda América. La obra se representa en 1574 a raíz de la consagración del arzobispo mejicano Moya de Contreras.

Sin embargo, desde nueve años antes, los Cabildos de la ciudad comienzan a otorgar premios, generalmente una joya de oro y plata, «de valor de hasta treinta escudos» ${ }^{6}$ a la mejor pieza teatral que se representase en las fiestas del Corpus de cada año. Tenemos noticias de que en 1575 obtiene esta recompensa en un certamen un tal Diego Juárez ${ }^{7}$, tal vez director de una compañía o acaso comediante también de la misma. Ello quiere decir, por los motivos que vamos a exponer más adelante, que se está fomentando de una manera decidida y con carácter ofi-

3 Agustín del Saz: Teatro hispanoamericano (Barcelona. Editorial Vergara. 1964, vol. I), pág. 22. El mismo autor señala que "la Constitución XXVI del Primer Concilio celebrado en Lima, en 1552 (ratificado en 1567), dice que no se hagan en las iglesias «representaciones ni velas de noche» que puedan ser motivo de escándalo". Ibídem, págs. 26 y 27.

4 Magaña, ob. cit., pág. 19.

5 Cfr. Magaña, P. Henríquez Ureña, Agustín del Saz, etc.

6 Magaña, ob. cit., pág. 21.

7 Ibídem., pág. 21. 
cial el desarrollo del teatro en Méjico. Junto al autor citado hay que unir el nombre de Fernán González de Eslava, lo que nos viene a certificar decididamente la idea de que la representación que ahora se hace continúa la inspiración religiosa pero, como dicen Kathleen Shelly y Grínor Rojo, «que lo es de una manera diferente, más depurada si se quiere al anterior» ${ }^{8}$. Los mismos autores han destacado la importancia que tiene para este teatro «el cultivo del entremés, la aparición de algunas palabras de origen americano, las referencias a costumbres regionales, unido todo ello a la alternancia de unos cuantos momentos cómicos en las piezas religiosas, son características que se privilegian de ordinario» ${ }^{9}$.

Los historiadores dan con frecuencia una posible nómina de autores, los «ingenios», de algunos de ellos sólo conocemos referencias a través de títulos de obras, pero se ignoran y desconocen los textos. Sirvan como ejemplos, en este sentido, los nombres de Luis Belmonte Bermúdez, Juan Bautista Corvera, Sancho Sánchez de Muñón, Gutierre de Cetina, del que se dice tan sólo que «residiendo en México hizo muchas obras que por su temprana muerte se perdieron, y entre ellas un libro de comedias morales en prosa y verso y otro de comedias profanas, y Juan de la Cueva, el sevillano, al que se le relaciona con cierto incidente ocurrido en la capital del virreinato con motivo del entremés del "Alcabalero» ${ }^{10}$.

Respecto a los actores que pudieron gozar del aplauso del público mejicano Agustín del Saz da el nombre del bachiller Villalobos, pero de manera lejana y muy desvaída. Se refiere a que «Los actores eran todos aficionados. Los había criollos y mestizos. Se dan noticias de algunos de ellos que fueron premiados por sus buenas actuaciones. El 17 de junio de 1588 un muchacho recibió cincuenta pesos de regalo por haber interpretado muy bien su papel en una comedia. Antes de la inauguración de la Casa de Comedias ya se conocía al bachiller Arias de Villalobos como empresario y autor. Por estas fechas se proponía a la ciudad un actor que recibiría dos mil pesos anuales» ${ }^{11}$. Más adelante cita a Gonzalo de Riancho y Antonio López Regalón. Por eso intentaremos perfilar con mayor nitidez la personalidad del primero, que es quien de verdad nos interesa, y distinguirlo como el actor más importante en Méjico en esta época a que nos estamos refiriendo.

Por lo que atañe a los lugares para las representaciones, fuera ya del templo, tenemos noticias sueltas y difusas, como la que suministra Magaña cuando alude a los primeros «tablados» públicos que se levantaron en los portales de las casas del Cabildo de la ciudad y en el atrio de la catedral ${ }^{12}$. La noticia no puede ser anterior al período que va de 1560 a 1563 , años en los que comienza a construirse el templo metropolitano de Méjico. De esta forma pues se deben datar las primeras fechas para la construcción de los escenarios sobre los cuales el público con-

8 Kathleen Shelly y Grínor Rojo: El teatro hispanoamericano colonial, en Historia de la literatura hispanoamericana (Madrid. Ediciones Cátedra. 1982), tomo I, pág. 319.

9 Ibídem., pág. 323.

10 Magaña, ob. cit., pág. 22.

11 Agustín del Saz: Teatro hispanoamericano, pág. 36.

12 Magaña, pág. 24. 
templaba la representación. Se sabe que el cabildo de la ciudad estipulaba al contratar con el director de la compañía las escenificaciones del Corpus y otras fiestas, la obligación de construir un tablado a su costa; se conoce por los datos que suministra Agustín del Saz que la asistencia masiva a una obra teatral en Etla, en 1575 , ocasionó el derrumbamiento del tablado levantado al efecto ${ }^{13}$; el mismo historiador da a conocer el nombre de Alonso de Buenrostro como experto en montaje de este tipo de escenarios ${ }^{14}$; Hildburg Schilling señala que estos tablados se engalanaban vistosamente, incluso con la abundancia que los primeros cronistas destacaron en la decoración de las calles y esquinas al paso de las procesiones del Corpus durante la labor misionera inicial, cuando dice: «Con certeza se puede aseverar que los tablados para las fiestas del Corpus Christi se adornaban con flores, como las representaciones precortesianas, pues en 1601 (la fecha que cita es interesante resaltarla por lo tardía) el intérprete Martín Albear recibió un salario de 50 pesos, entre otras cosas, porque su ocupación era aderezar los tablados de rrosas y flores... los días del Corpus y el día de San Ypólito» ${ }^{15}$.

En la referencia que se hizo a la contratación del ya citado Andrés Laris de Durango, en 1597, por parte del cabildo para la representación que se había concertado, se especifica el pago de seiscientos pesos «de oro común» y construir el tablado: "para la cual el cabildo ordenó al carpintero Juan de Saucedo hacer todos los tablados para la fiesta del Corpus y tablero de birrey y audiencia y damas, según y como hasta aquí se ha hecho, y el plan del tablado de la comedia con el espaldar del vestuario aforrado de tablas». Para esa fecha, afirman Magaña Esquivel y Lamb, «existía cuando menos una casa de comedias» ${ }^{16}$. Esta aseveración no se puede corroborar totalmente, como ahora veremos, y sí tiene más sentido el dato que proporciona Pedro Henríquez Ureña, cuando señala que en ese mismo año «se edificó teatro (el de Francisco de León) y se estilaban fiestas y comedias nuevas cada día, según recoge del testimonio de Bernardo de Balbuena» ${ }^{17}$. Esta casa de comedias de León en la ciudad del virreinato es la misma a la que alude Guillermo Lohmann al retrasar la fecha de construcción de un patio para las representaciones en Lima, haciendo referencia a un corral que se prepara «muy pocos años después de que en Madrid se habían inaugurado el de la Cruz y el del Príncipe, siendo a su turno Lima - dice Lohmann - la primera ciudad indiana que disfrutó de semejante privilegio, pues en la capital de la Nueva España, erigió Francisco de León la primera Casa de Comedias, recién en

13 Ibidem., pág. 27.

14 Ibídem., pág. 27.

15 Hildburg Schilling: Teatro profano en la Nueva España. Fines del siglo XVI a mediados del siglo XVIII (México. Universidad Autónoma de México. Centro de Estudios Literarios. Imprenta Universitaria), 1958, pág. 52. (La referencia de Schilling está tomada de las Actas del Cabildo de la ciudad de Méjico, tomo XIV, pág. 199).

16 Magaña, ob. cit., pág. 24 y sig.

17 Vid. Pedro Henríquez Ureña: El teatro en la América colonial, en Obra crítica (México. Fondo de Cultura Económica. 1960), pág. 275. 
1597, colindante con el Hospital de Nuestra Señora» ${ }^{18}$. La localización urbana del entorno también la refiere Rojas Garcidueñas ${ }^{19}$.

Hasta aquí, con las expresadas noticias, lo más importante que se conoce del comienzo, desarrollo y nivel alcanzado en las representaciones escénicas en la ciudad de Méjico durante el siglo XVI. La omisión de otros datos en estas líneas obedece tan sólo a evitar la reiteración en testimonios, por otra parte escasos y siempre muy fragmentarios, sobre los que inciden la mayor parte de los autores que han estudiado el desenvolvimiento del género teatral en Nueva España durante la época de la colonia.

Sin embargo, en este momento estamos en condiciones de aportar curiosas referencias documentales sobre la materia en el período que se analiza, con las que creo arrojar alguna luz sobre este tema durante la significativa transición del siglo XVI al XVII, centuria esta última en la que el teatro en Méjico arraiga con fuerza y ahonda sus raices para comenzar a dar enseguida excelentes frutos. Sólo los nombres de Juan Ruíz de Alarcón y Juana Inés de la Cruz, entre otros, pueden certificarlo. Se trata de una interesante «Información de Gonzalo de Riancho y Francisco de León, para que puedan representar en la ciudad de México en sus casas» ${ }^{20}$. Así se expresa el documento que se guarda en el Archivo General de Indias, de Sevilla, que paso a comentar a continuación.

La mencionada «información» consta de siete folios manuscritos, más una portadilla, donde se incluye la petición que los citados Gonzalo de Riancho, actor y director de compañía teatral, mancomunadamente con Francisco de León, propietario de la casa de comedias en la ciudad de Méjico, solicitan al virrey don Gaspar de Zúñiga y Acevedo, conde de Monterrey, para que «se les de licencia para por tiempo de seys años puedan rrepresentar en la Nueva España los domingos y fiestas y dos días en la semana. Y los domingos y fiestas de la mitad de la quaresma». La instancia está fechada en 16 de junio de 1599 y va acompañada de las declaraciones que hacen los testigos, lo que suministra importantes datos y arroja suficiente luz como para iluminar con claridad esta parcela de la historia teatral en el espacio geográfico que se estudia. Las declaraciones de los testigos se hacen ante el alcalde ordinario de aquella ciudad Rodrigo de Zárate y Villegas, todo ello refrendado por Juan Pérez de Rivera, escribano público, entre los días ocho y veinticuatro de noviembre de 1597 . Dicha documentación se trasladó al virrey citado y pasó al Consejo de Indias para que informase sobre lo que más convenía en el asunto y petición.

Se trata pues de conseguir cédula real por la que se autorizase a ambos personajes del teatro mejicano disfrutar un permiso exclusivo para poder representar durante un período de seis años en todo el territorio mejicano, y en la ciudad capitalina en concreto, únicamente en la casa propiedad de Francisco de León,

18 Guillermo Lohmann Villena: El arte dramático en Lima durante el Virreinato (Madrid. Escuela de Estudios Hispano-Americanos de Sevilla. 1945), pág. 68.

19 El teatro en la Nueva España en el siglo XVI (México, 1935), pág. 121.

20 Archivo General de Indias de Sevilla. Audiencia de México, legajo 3177. (Las referencias a dicha «Información» vendrán dadas desde ahora tan sólo por la paginación de los folios). 
durante los días habituales para la escenificación de comedias, más dos días entre semana y los domingos y fiestas en la primera mitad de la época de Cuaresma, es decir, después de Carnaval y antes de la Semana Santa, durante la cual se representarían, como se expresa, "farsas divinas», y añade: «como es uso y costumbre» y como está aprobado por el Santo Oficio de la dicha Nueva España. El mencionado Riancho pide también durante dos años ser la única compañía de comedias que pueda montar obras teatrales, para lo cual «offrece de servir a vuestra alteza con ochocientos pesos en cada un año de representación», pagados, dicen los peticionarios, en su «real caxa de la dicha ciudad».

De la solicitud podemos sospechar que al final del siglo XVI en Méjico había un decidido y probado interés por parte del público hacia las representaciones teatrales, como demuestra la valentía económica que supone llevar a cabo la concesión de la gracia, en caso que se produjera, debido a la cantidad que arriesgaban Riancho y León. Esta petición sugiere además que la hacían personas muy conocidas en el virreinato dentro del campo profesional a que se refiere, si se quería tener un mínimo de éxito asegurado para conseguir lo que se pedía. Y, en último lugar, se está planteando la hipótesis de que empezaba a existir en el mundo teatral de Méjico una fuerte competencia por representar obras escenificadas; la realidad es que la presencia de nuevas compañías de cómicos, no solamente llegados de la península sino de origen criollo, se disponían a competir artísticamente ante un público interesado cada vez más por el fenómeno teatral. La consiguiente evolución del género en las ciudades del virreinato, principalmente en la capital, durante el siguiente siglo, prueba de manera elocuente los riesgos y venturas que sufrieron y disfrutaron las compañías teatrales por querer adaptarse al gusto e interés de los públicos de la época.

Los seis testigos que declaran en la información tomada en 1597 , son los siguientes: Juan Pérez de Ribera, escribano público de la ciudad de Méjico, de treinta años poco más o menos; don García de Gante, residente en la capital del virreinato, de clara ascendencia flamenca ${ }^{21}$, de treinta años también, quien declara que conoce a los susodichos Riancho y León «de más de tres años a esta parte» ${ }^{22}$, según se expresa en su declaración ante el escribano; Francisco de Monzón, vecino y mercader en la capital, de más de cuarenta años; Benito Beltrán, vecino de Méjico y escribano del rey, también de más de cuarenta años; y el último de los declarantes, Cristobal de Medina, procurador de la Audiencia Ordinaria de la ciudad de Méjico, de más de treinta y cinco años, quien conoce a los mencionados peticionarios desde hace más de diez años a esta parte, por lo que su información posee el interés de remontarse casi hasta los primeros años en que el teatro en Méjico comienza a tener casa propia ${ }^{23}$.

Las preguntas que les hacían eran de diversa índole, además de las generales de la ley. Estas giran en torno a los temas que a continuación se expresan: en pri-

21 Muy vinculado al mundo teatral en el Virreinato de Nueva España, debo citar aquí a fray Pedro de Gante, emparentado tal vez por su origen con el mencionado testigo.

22 fol. 3.

23 fol. 3 vto. 
mer lugar si sabían que Gonzalo de Riancho había sido el primero que en la ciudad había fundado casa de comedias, en la cual «se representaba como se a echo de diez años a esta parte con mucho gusto y satisfaçion desta ciudad con toda desencia y honestidad» ${ }^{24}$ y gastando grandes sumas de dineros. Otra pregunta se hace en orden a saber si la compañía de Riancho había representado las comedias «questa ciudad hordena se hagan los días del Corpus conforme al uso de Castilla y otras fiestas de la çiudad, lo qual se a echo con mucho aplauso y gusto della y de todos los ciudadanos» ${ }^{25}$. Igualmente versaban si sabían que Francisco de León había comprado una casa donde hizo un teatro «muy abentajado donde estubiesen las mugeres aparte de los hombres» ${ }^{26}$ y en la que había gastado más de once mil pesos en su edificación y adaptación. Y por último se preguntaba a los testigos si creen conveniente que las representaciones se pudiesen ampliar a otros días de los que estaban obligados a actuar, y de los beneficios morales que se podían obtener de ello.

De lo expuesto por los testigos hemos de obtener los siguientes resultados:

Por lo que se refiere a Gonzalo de Riancho sabemos que gozaba desde hacía tiempo de tener fama de hombre honrado, de carácter agradable y amigo de dar gusto a todos; que fue «el primer fundador de la casa de la farsa», datos sumamente interesantes tanto para conocer con más detalle la fecha en que las comedias tenían casa propia, así como del nombre con el que se le designa a final del siglo a un «corral» en el Méjico del virreinato; asimismo se tiene ya la certeza de que llevaba representando en ella diez años, es decir, desde 1587, fecha que se puede dar como definitiva en este sentido; que lo hacía también con compañía propia, dato muy interesante este último y que con ella ha venido representando en las fiestas que la ciudad tiene establecidas, tales como el Corpus, su octava y el día de San Hipólito, en cuya festividad se conmemoraba la fecha del 13 de agosto de 1521 en que se rindió Technotitlán a Hernán Cortés. De Riancho sabíamos que era sevillano, según el testimonio de Schilling ${ }^{27}$, quien además lo documenta, en algunas ocasiones, con el nombre de Pedro, lo que debe ser una mala lectura del texto. Es también el mismo Schilling quien advierte que Juan de la Cruz, tal vez en colaboración con Francisco Manuel de Villafuerte, dirigió la primera compañía que actuó en Puebla de los Angeles, según los datos que recoge de sus investigaciones en el Archivo del Cabildo de aquella ciudad mejicana por el año $1596^{28}$, lo cual nos sirve para empezar a recomponer el número de compañías teatrales que actuaban en el virreinato por aquellos años. De esta forma el autor del Teatro profano en la Nueva España, advierte: "Aparentemente las dos compañías de renombre podían dar abasto a las necesidades capitalinas de diversión. Riancho y Alonso Vázquez, dice, no toleraban a otro contrincante a su

24 fol. 2.

25 fol. 2.

26 fol. 2.

27 Schilling: Teatro profano..., pág. 69.

28 Cfr. Schilling, ob. cit., 68 (No hay ninguna referencia a la compañia teatral de Gonzalo de Riancho en ningún año del siglo XVI mejicano). 
lado. Con todo, si el ofrecimiento del cabildo de la ciudad de Puebla era más ventajoso que el del cabildo de México, los actores capitalinos solían aceptar el primero, habiendo solicitado previamente el permiso respectivo para salir de la capital» ${ }^{29}$. Pero esto ocurría ya en 1605 .

De todas formas, los datos que dan los testigos en la «información» que comentamos resaltan todos ellos la personalidad teatral que tenía Gonzalo de Riancho y las noticias son suficientes para suministrar y aclarar los datos que permiten conocer el papel que representó en el desarrollo del teatro mejicano.

Por lo que concierne a Francisco de León, las respuestas corroboran los datos que ya se poseían sobre él, tales como el ser dueño de la primera casa de comedias en la ciudad de Méjico, cuyo local compró, para posteriormente «la aver echo desde los çimientos» ${ }^{30}$, y la adaptó después a las representaciones, así como los gastos que tuvo para ponerla en funcionamiento. Ahora podemos saber, según el testimonio que da don García de Gante, que en ella hizo «aposentos altos», lo que comprueba asimismo Francisco de Monzón en el sentido de que en dicha casa se habían labrado "corredores», todo ello para que las mujeres estuviesen separadas de los hombres y con recogimiento, dice uno de ellos; y Benito Beltrán especifica este pormenor, aclarando: «de suerte que no se puedan comunicar los unos y los otros» ${ }^{31}$; resaltan los declarantes la comodidad y el orden que existía en el local, así como, en palabras de Cristobal de Medina, «la casa es una de las mejores que ay en Castilla por averlas visto este testigo alla y eçede esta a ellas por la linpieça y compostura que tiene y la buena horden y traza quel dicho Francisco de León dio en los rrepartimientos della...» ${ }^{32}$, incluso otro dato creemos también interesante de resaltar, tal como el que señala en su declaración don García de Gante, quien califica la casa de comedias a que nos referimos de «tan buena que con haber este testigo visto casas de España, de Madrid, Sevilla y otras, no ha visto otra que le haya parecido tan buena como ella...» ${ }^{33}$.

Juan Pérez de Ribera aclara aun más estas circunstancias, cuando afirma que «en esta ciudad algunas personas que hacían comedias no eran de consideración, ni tenían casa diputada para ello, ni vestuario» ${ }^{34}$. En este sentido, el mencionado Beltrán puntualiza en su declaración que la compañía es muy buena y tiene vestuario "para todas las figuras que en ella salen» ${ }^{35}$ y donde "el dicho Riancho reçita» ${ }^{36}$; aun es más curiosa la aclaración que se hace sobre la importancia de las comedias en este momento; así se especifica que: «tiene por cosa muy conveniente y de mucha utilidad y provecho que las dichas representaciones vayan en continuación, así los días de fiesta como los de entre semana, porque este testigo

Schilling, ob. cit., pág. 72 .

30 fol. 5 vto.

31 fol. 5 vto.

32 fol. 6 .

33 fol. 3 vto.

34 fol, 2 vto.

35 fol. 5 .

36 fol. 5 vto. 
tiene por jurisprudencia (debe recordarse que el testigo era escribano público) en lo que ha visto que de la mucha gente que se recoge a oirlas se excusan muchos juegos, vicios y otros pecados públicos en servicio de Dios Nuestro Señor, porque esta ciudad no tiene otros ninguno entretenimiento, ni parte de pasatiempo y si las dichas comedias cesasen toda la gente que allí se recoge es cosa cierta se han de ocupar en juegos... ${ }^{37}$.

Ignoro la suerte que corrió la petición de Riancho y Francisco de León dirigida al virrey de Méjico, conde de Monterrey, pero hay que sospechar que no consiguió su propósito. Es muy significativo que el día 11 de febrero de 1601, dos años después de ser elevada la petición al Consejo de Indias, el mismo gobernante dispuso que «Xptval Peress a cuyo cargo está la casa de la comedia, dé honsse pessos cada día de fiesta» ${ }^{38}$; y un año después, el mismo Cristobal Pérez «dueño que dice ser de las dos casas donde se representan las comedias en esta ciudad», pide que se le conceda la autorización exclusiva de las representaciones en estas dos casas de su propiedad, porque endeudado como estaba "si se representase en otras casas, como pretenden algunas personas, sería su total destruición» ${ }^{39}$. Parece que el virrey accedió a conceder dicha petición. Esa referencia a «algunas personas», tal como se expresa en el texto, está claro que alude a los dos peticionarios que aquí se han comentado.

De todas formas, el auge de las comedias en Méjico comenzaba una trayectoria ascendente en el nuevo siglo con datos y noticias más abundantes, como es lógico, que en la centuria anterior, aumentando las casas de comedias, las compañías de actores y las ilusiones y fracasos que siempre fueron juntos y acompañaron al carro de la farándula.

37 fol. 3.

38 La cita se documenta en el Archivo General de la Nación. General de Parte, tomo V, fol. 282 vto. México, y la utiliza Schilling en ob. cit., 15.

39 Cfr. Schilling, ob. cit., pág. 16. 


\section{INFORMACION DE GONZALO DE RIANCHO Y FRANCISCO DE LEON, PARA QUE PUEDAN REPRESENTAR EN LA CIUDAD DE MEXICO EN SUS CASAS}

Archivo General de Indias. Sevilla Audiencia de México, legajo 3177.

/PORTADA:/ Barbadillo + 1599

Gonçalo de Reancho y Francisco de Leon vecinos de México. Suplican se les de licencia para que por tiempo de seys años puedan rrepresentar en la Nueva España los domingos y fiestas y dos dias en la semana. Y los domingos y fiestas de la mitad de la quaresma. Por lo qual ofrezen de servir con ocho [sic] pesos cada un año para quien su ma/gestad/ los quisiere aplicar.

Trae ynformacion de testigos echa en Mexico ante un alcalde ordinario.

Que es el 1. que alli representa.

Que a 10 años que lo hace con mucho gusto y satisfaçion de la çiudad y vecinos della.

A echo las fiestas del Corpus y otras que se le an ordenado. Que conpro una casa en Mejico para ello y con ella un teatro muy bueno.

Lo 2 : que por los 2 años primeros que .../roto/

el rrepresentare no pueda representar otro autor alguno. Ofreçe 800 pesos en cada un años .../roto/ presentaçion.

Lo $3^{\circ}$. pide çedula para que aten... / roto/ cho que a gastado en las cosas .../roto/ que a hecho para representar en ella en otra parte se represente.

Relator licenciado Sant Andres. 
Parecer del alcalde ordinario de Méjico

Que el que pide tiene la casa y teatro donde se rrepresentan.

Ques de gran utilidad las rrepresentaçiones para entretener la gente de la ciudad.

$\mathrm{Y}$ apartallos de juegos y otros vicios aciendoles la merced que pide. Expediente.

/al dorso:/

Gonzalo de Reancho y Francisco de León vecinos de la ciudad de Mexico.

Secretario Ibarra

/f ${ }^{\circ} 1 /$ / Por dos reales de derechos. En 14 de junio 1599. San Andres /rúbrica/

Muy poderoso Señor

Gonzalo de Reancho y Francisco de Leon vecino de la ciudad de Mexico dicen que como consta y parece por la ymformacion y recaudos de que hazen presentacion, el dicho Gonzalo de Reancho fue el primer fundador de la casa de la farsa en la dicha ciudad de Mexico donde de diez años a esta parte con su compañia a representado y representa con mucho gusto y aprobacion de todos los vezinos de la dicha ciudad con toda honestidad y decencia. De mas de lo qual a representado y representa las comedias, que la ciudad le a ordenado los dias del Corpus y otras fiestas de la ciudad a uso de estos Reynos con mucho gusto y aplauso della. De lo qual se a seguido mucho provecho y utilidad a la republica mexicana, porque se an evitado y evitan muchos juegos y vicios. Y el dicho Francisco de Leon para que se representasse como asta agora con licencia del Virrey, compro unas casas donde hizo un teatro muy apto para la representacion, y assientos divididos para que las mugeres estuviessen apartadas de los hombres, goardando en todo mucha onestidad y buena compossicion, en que gasto como todo consta y paresce por esta imformaçion mas de once mill pesos de oro comun. A vuestra alteza piden y suplican se les haga merced de dar su real cedula para que el $/ \mathrm{f}^{\circ} 1 \mathrm{v}^{\circ} /$ dicho Gonzalo de Reancho por tiempo de / seys años pueda representar con su compañía en la Nueva España todas las fiestas 
y domingos del año, con dos dias entre semana, y los domingos y fiestas de la mitad de la quaresma con los dos dias entre semana farsas divinas como es uso y costumbre con aprobación del santo officio de la dicha Nueva España. Otrosi pide y supplica a vuestra alteza el dicho Gonzalo de Reancho que por los dos años primeros, donde el representare no pueda representar otro actor alguno, el qual offrece de servir a vuestra alteza con ochocientos pesos en cada un año de representacion, para lo que vuestra alteza los quisiere aplicar, pagados en su real caxa de la dicha ciudad. Otrosi el dicho Francisco de Leon pide y supplica a vuestra alteza atento a lo que a gastado en las dichas casas de representación, le haga merced de darle cedula real para que solamente en sus casas y no en otras de México se pueda representar. En lo qual recibirá merced y para ello etc.

\section{$+$}

Que se comete al virrey y audiencia de Méjico para que sobre todo probean lo que conbiniere y avisen de lo que hacen al qonsejo en 16 de junio de 1599.

\section{El licenciado Sant Andres /Firma y rúbrica/}

$/ f^{\circ} 2 /$

I +

En la çiudad de Mexico a ocho dias del mes de nobienbre de mill y quinientos y noventa y siete años ante Rodrigo de Çarate y Villegas alcalde hordinario desta dicha çiudad se leyo esta petiçion. Gonçalo de Riancho y Francisco de Leon vecino desta çiudad dezimos que a nuestro derecho conviene se nos rreçiba ynformaçion de lo conthenido en estas preguntas que presentamos para en guarda de nuestro derecho.

A vuestra merced pedimos y suplicamos mande se nos resçiba de la qual se nos de uno o dos treslados autorizados en publica forma en manera que hagan fee que en ello resçibiremos bien y merçed con justicia.

Ynterrogatorio Yten si saben que yo el dicho Gonzalo de Riancho fuy el primero El $1^{\circ}$ que alli rrepresenta. que en esta çiudad fundo casa en la qual se representava como se a echo de diez años a esta parte con mucho gusto y satisfaçion desta ciudad con toda desencia y honestidad en que e gastado grande suma de pesos de oro. Digan lo que saben.

Yten si saben que ansimismo e hecho y representado con mi compañia las comedias questa ciudad hordena se hagan los dias del Corpus conforme al uso de Castilla $y$ otras fiestas de la çiudad, lo qual se a echo con mucho aplauso y gusto della y de todos los ciudadanos. Digan lo que saben. 
Yten si saben que para que las dichas comedias que con licencia del Virrey desta Nueva España se rrepresentan por el discurso del año se hiziesen con toda desençia y hornato yo el dicho Francisco de Leon conpre una cassa en la qual hize un teatro muy abentajado donde estubiesen las mugeres aparte de los honbres que las oyesen para que en todo ubiese la conposiçion nesçesaria en lo qual e gastado mas de honze mill pesos. Digan lo que saben. Yten si saben que seria conbiniente que las dichas representaçiones se continuasen como se haze los dias de fiesta y un dia entre semana porque con las comedias an çesado muchos y grandes juegos que avia en esta çiudad. Digan etc.

Yten si saben que todo lo suso dicho es publico y notorio publica vos y fama. Gonzalo de Riancho.

El alcalde mando que se le rreçiba al dicho Gonzalo de Riancho y Francisco de Leon la ynformaçion que ofresçen y cometio el exsamen de los testigos a qualquier / escrivano real y le dio comision en forma y fecha se les de a los suso dichos los treslados que quisieren autorizados en publica forma en lo qual interponia e ynterpuso su auturidad u decreto judiçial y lo firmo de su nonbre Rodrigo de Çarate y Billegas Juan Perez de Ribera scriuano publico.

Testigo. En la çiudad de Mexico a quinze dias del mes de nobienbre de mill y quinientos y noventa y siete años Gonzalo de Riancho y Francisco de Leon para la dicha ynformaçion presento por testigo a Juan Perez de Ribera scriuano publico desta dicha çiudad del qual se rreçibio juramento y el lo hizo por Dios Nuestro Señor e por una señal de cruz so cargo del qual prometio de dezir verdad e preguntado por las preguntas del interrogatorio dixo lo siguiente:

1. A la primera pregunta dixo que conosçe a los dichos Gonzalo de Riancho e Francisco de Leon de mas de diez años a esta parte. Preguntado por las preguntas generales de la ley dixo que no le tocan e ques de hedad de treynta años poco mas o menos.

2. A la segunda pregunta dixo que lo que della sabe es que aunque en esta çiudad algunas personas hazian comedias no heran de consideracion ni tenian casa diputada para ello ni bestuario e del tienpo quel dicho Gonzalo de Riancho dize poco mas o menos hasta agora a visto este testigo como el suso dicho a tenido en esta dicha çiudad casa particular en la qual a echo muchas e muy buenas representaçiones con toda desencia y onestidad con buen bestuario a las figuras que en ellas salen de manera que le pareçe a este testigo que en ello a gastado el suso dicho mucha suma de pesos de oro y esto rresponde.

3. A la terçera pregunta dixo queste testigo a visto que algunos años el dicho Gonzalo de Riancho con su conpañia an echo las come- 
dias que esta çiudad e cavildo della a hordenado se hagan los dias del Corpus y otras fiestas de la çiudad conforme al uso de Castilla lo qual a echo con mucho aplauso e gusto de los vecinos desta rrepublica y esto rresponde.

4. A la quarta pregunta dixo que sabe este testigo quel dicho Francisco de Leon para que se hiziesen las dichas comedias y se rrepresenten con liçençia del Virrey desta Nueva España conpro unas cassas en esta dicha çiudad y a echo en ellas comodidad y horden para que se rrepresenten las dichas comedias teniendo aposentos altos y dibididos para las mugeres de manera que no estan con

Testigo. los hombres, / y para el propósito le pareçe a este testigo que la mayor casa que se puede hazer y de personas de Castilla a savido que ninguna ay en ninguna çiudad de Castilla tan prençipal como ella en lo qual le paresçe a este testigo a gastado el dicho Francisco de Leon mucha suma de pesos de oro, y esto responde.

5. A la quinta pregunta dixo queste testigo tiene por cossa muy conbiniente y de mucha utilidad y probecho que las dichas rrepresentaçiones vayan en continuaçion ansi los dias de fiestas como los de entre semana porque este testigo tiene por yspurençia en lo que a visto que de la mucha gente que se rrecoge a oyllas se escusan muchos juegos viçios y otros pecados publicos en des serbiçio de Dios Nuestro Señor porque esta çiudad no tiene otros ninguno entretenimientos ni partes de pasatienpos y si las dichas comedias çesasen toda la gente que alli se rrecoge es cossa çierta se an de ocupar en juegos y en otros malos entretenimientos y al dicho Gonzalo de Riancho se le avia de dar mucho premio porque asistiese en esta dicha çiudad a hazer las dichas representaçiones y comedias para gusto y entretenimiento de los dichos vecinos y abitantes en ella demas de ques honbre honrrado y muy agradable y amigo de hazer gusto a todos y esto rresponde desta pregunta y es la verdad para el juramento que fecho tiene en que se rretifico e firmolo de su nonbre. Juan Perez de Rivera. Paso ante mi Juan Alonso scrivano rreal.

En la çiudad de Mexico en este dicho dia mes y año dicho, el dicho Gonzalo de Riancho y Francisco de Leon para la dicha ynformaçion presentaron por testigo a don García de Gante reçidente en esta dicha çiudad del qual se rresçibio juramento y el dicho lo hizo por Dios Nuestro Señor e por una señal de cruz so cargo del qual prometio de dezir verdad, e preguntado por el ynterrogatorio dixo lo siguiente:

1. A la primera pregunta dixo que conosçe a los dichos Gonzalo de Riancho e Francisco de Leon que le presentan por testigo de mas de tres años a esta parte.

Preguntado por las preguntas generales de la ley dixo ques de hedad de treynta años poco mas o menos y no le tocan las generales de la ley. 
2. A la segunda pregunta dixo queste testigo a oydo dezir en esta dicha çiudad por publico y notorio quel dicho Gonzalo de Riancho fue el primero que tubo cassa de asiento en esta dicha çiudad en que hazia sus comedias por que las demas personas que en ella las hazian no las tenian de asiento. En lo qual el dicho Riancho a dado y da mucho gusto a los vecinos desta dicha çiudad teniendo como tiene buena gente y aparatos de bestidos para ello / e comedias en lo qual no puede aver dexado de gastar mucha suma de pesos de oro, lo qual a echo toda desençia y onestidad porque las comedias quel suso dicho a echo an sido muchas y buenas que dentro en España no se podian aver echo mejor por aberlo visto este testigo aca y alla y en la corte y esto rresponde.

3. A la terçera pregunta dixo que del tienpo queste testigo a en esta çiudad a visto que las fiestas que la dicha çiudad e cavildo an echo el dia de Corpus y otras fiestas que se an ofreçido en ellas hasta quel suso dicho salio della las a echo el dicho Gonzalo de Riancho con su compañia conforme al uso que en España se suele tener en las tales fiestas y con mucho aplazo y hornato que se suele hazer en las partes despaña y con mucho gusto de los çiudadanos dellas por que lo a oydo dezir este testigo publicamente hallandose en las dichas fiestas y esto rresponde.

4. A la quarta pregunta dixo queste testigo sabe y a oydo dezir que para el efecto que las dichas comedias se hiziesen con el rrecogimiento nesçesario Francisco de Leon avia conprado unas cassas en esta dicha çiudad y en ellas an echo aposentos altos adonde las mugeres estubiesen divididas de los honbres y con rrecogimiento $\mathrm{y}$ al presente se haze una puerta de por si por donde entren las dichas mugeres porque no se encuentren con los honbres, en lo qual a oydo dezir este testigo publicamente que a gastado el suso dicho honze mill pesos de oro comun por aver echo en ellas el hornato nesçesario para el dicho efeto y ser tan buena que con aver este testigo visto las cassas despaña de Madrid, Sevilla y otras no a visto otra que le aya pareçido tan buena como ella y esto responde.

5. A la quinta pregunta dixo queste testigo tiene por çierto que sera cosa muy justa e provechosa que las dichas comedias se prosigan en los dias de fiesta y entre semana respeto de que la gente que entra en las dichas comedias se evita de que bayan a jugar y otros vicios publicos respeto de que en esta çiudad no ay entretenimiento ninguno y ninguna junta se haze que no sea para jurar y con las dichas comedias çesan todos los dichos ynconbinientes y lo tiene por çierto y lo a oydo dezir a otras muchas personas y esto es lo que sabe y la verdad para el juramento que hizo e firmolo de su nonbre. Don García de Gante. Paso ante mi Juan Alonso escrivano real. 
/fo 4/ Testigo. En este dicho día mes y año dicho, el dicho Gonzalo de Riancho para la dicha ynformaçion presentó por testigo a Christoval de Heredia scrivano del rey nuestro señor del qual se rreçibio juramento y el lo hizo por Dios Nuestro Señor e por una señal de cruz so cargo del qual prometio de dezir verdad e preguntado por las preguntas del ynterrogatorio dixo lo siguiente:

1. A la primera pregunta dixo que conosçe al dicho Gonzalo de Riancho y a Francisco de León desde quel dicho Gonzalo de Riancho vino a esta çiudad de los rreynos de Castilla. Preguntado por las preguntas generales de la ley dixo ques de hedad de mas de veynte y seys años y no le tocan las generales.

2. A la segunda pregunta dixo que lo que della sabe es que aunque en esta çiudad algunas personas hazian comedias no heran de consideraçion ni tenian casa de asiento y diputada para ello ni bestuario y del tienpo quel dicho Gonzalo de Riancho dize poco mas o menos hasta agora a bisto este testigo como el suso dicho a tenido en esta dicha çiudad casa particular en la qual a echo muchas y muy buenas representaçiones con toda desençia y onestidad y con buen vestuario a las figuras que en ellas salen de manera que le pareçe a este testigo que en lo suso dicho a gastado mucha suma de pesos de oro, y esto rresponde.

3. A la terçera pregunta dixo queste testigo a visto que algunos años el dicho Gonzalo de Riancho con su conpañia a echo las comedias que en esta çiudad el cavildo della a hordenado se hagan los dias del Corpus y otras fiestas de la ciudad conforme al uso de Castilla lo qual a echo con mucho aplazo e gusto de los vezinos desta rrepublica y esto rresponde.

4. A la quarta pregunta dixo que sabe este testigo quel dicho Francisco de Leon para que se hiziesen las dichas comedias y se rrepresentasen con licençia del Virrey desta Nueva España conpro unas cassas en esta dicha çiudad y a echo en ellas comodidad y horden para que se rrepresenten las dichas comedias tenia aposentos altos y dibididos y apartados para las mugeres de manera que no estan con los honbres y para el proposito le pareçe a este testigo ques la mejor casa que se puede hazer y tan buena como las que ay en Sevilla las que este testigo a visto en lo qual le pareçe a este testigo que a gastado mucha cantidad de pesos de oro rrespeto de ser tan buena como es y esto rresponde.

5. A la quinta pregunta dixo queste testigo tiene por cossa muy conbiniente y de mucha utilidad y provecho que las dichas rrepresentaçiones vayan en continuaçion ansi en los dias de fiesta como los de entre semana por que este testigo tiene por yspirençia $/ \mathrm{f}^{\circ} 4 \mathrm{v}^{\circ} /$ en lo que a visto que de la mucha gente / que se coge a oyrlas se escusan muchos juegos y viçios y otros pecados publicos en des servizio de Dios Nuestro Señor por questa çiudad no tiene 
ningunos entretenimientos ni partes de pasatienpos y si las dichas comedias çesasen toda la gente que alli se rrecoge es cosa çierta se an de juntar e ocupar en juegos y otros malos entretenimientos y al dicho Gonzalo de Riancho se le avia de dar mucho premio porque asistiese en esta dicha çiudad a hazer las dichas rrepresentaçiones y comedias para gusto y entretenimiento de los dichos vecinos y abitantes desta dicha çiudad de mas de ques honbre honrrado y muy agradable y amigo de dar gusto a todos y esto es lo que sabe y la verdad para el juramento que fecho tiene y firmolo de su nombre. Christoval Ramirez de Heredia. Paso ante mi: Juan Alonso scrivano rreal.

Testigo. $\quad$ E despues de lo suso dicho en este dicho dia, mes y año dicho, el dicho Gonzalo de Riancho para la dicha ynformaçion presentó por testigo a Francisco de Monçon vecino e mercader desta dicha çiudad del qual se rrecibio juramento y el lo hizo por Dios Nuestro Señor e por una señal de cruz so cargo del qual prometio de dezir verdad e preguntado por las preguntas del ynterrogatorio dixo lo siguiente:

1. A la primera pregunta dixo que conosçe a los dichos Francisco de Leon y Gonzalo de Riancho de diez años a esta parte poco mas o menos.

Preguntado por las preguntas generales de la ley dixo ques de hedad de quarenta años poco más o menos y no le tocan las generales.

2. A la segunda pregunta dixo queste testigo del dicho tienpo de diez años a esta parte a visto quel dicho Gonzalo de Riancho a tenido en esta dicha çiudad cassa de asiento y para el efeto de que se hiziesen las dichas comedias porque los demas no tenian el dicho asiento lo qual a echo el dicho Gonzalo de Riancho con todo rrecogimiento y onestidad y tiene mucho hornato de bestidos para el dicho efeto en lo qual sabe este testigo que a gastado mucha suma de pesos de oro, y esto rresponde desta pregunta.

3. A la terçera pregunta dixo queste testigo sabe que del dicho tienpo quel dicho Gonzalo de Riancho a estado en esta dicha çiudad a echo de hordinario en ella las rrepresentaçiones que se an echo los dias del Corpus y otras fiestas que se an ofreçido en esta dicha çiudad el suso dicho y su gente segun se usa en Castilla y otras partes con gran gusto y aplauso de los ciudadanos desta dicha çiudad por aberlo visto este testigo e oydolo dezir a otras muchas personas quando se hazian los dichos autos y esto responde a esta pregunta.

4. A la quarta pregunta dixo que para el dicho efeto de que se hiziesen / las dichas comedias con licençia del Virrey desta Nueva España sabe este testigo que Francisco de Leon conpró en ella unas casas en la qual a labrado aposentos y corredores altos para don- 
de esten las mugeres aparte de los honbres con mucho recogimiento y es tan buena queste testigo no a visto en esta çiudad ni en los Reynos de Castilla otra mejor para el dicho ministerio, en lo qual le pareçe a este testigo quel dicho Francisco de Leon a gastado mucha cantidad de pesos de oro, y esto rresponde.

5. A la quinta pregunta dixo que le paresçe a este testigo ques util y provechoso que se hagan las dichas comedias como se hazen los dias de fiesta y algunos entre semana respeto que con las dichas comedias çesan los juegos y otros biçios publicos que se harian respeto de los pocos entretenimientos que en esta çiudad ay los dias de fiesta y con lo suso dicho çesa todo ello y lo a visto por yspirençia este testigo y esto es lo que sabe y la verdad para el juramento que fecho tiene y firmolo de su nonbre. Francisco de Monçon. Paso ante mi: Juan Alonso scrivano real.

Testigo. En la çiudad de Mexico a diez y ocho dias del mes de nobienbre de mill y quinientos y noventa y siete años Gonzalo de Riancho para la dicha ynformaçion presento por testigo a Benito Beltran vezino y escrivano del rrey nuestro señor desta dicha çiudad, so cargo del qual prometio de dezir verdad y preguntado por las preguntas del ynterrogatorio dixo lo siguiente:

1. A la primera pregunta dixo que conosçe al dicho Gonzalo de Riancho y Francisco de Leon de diez años a esta parte poco mas o menos.

Preguntado por las preguntas generales de la ley dixo ques de hedad de mas de quarenta años y no le tocan las generales de la ley.

2. A la segunda pregunta dixo que del dicho tienpo de diez años a esta parte que a quel dicho Gonzalo de Riancho estaban esta dicha çiudad le a visto que a tenido y tiene casa señalada en que haze sus comedias por que los demas que de antes las hazian no heran de consideraçion ni tenian casa diputada para ello ni bestuarios como el dicho Gonzalo de Riancho los tiene para todas las figuras que en ella salen el qual a echo y haze muchas y muy buenas representaçiones con mucho gusto y contento de los vecinos desta dicha çiudad en lo qual a gastado el dicho Gonzalo de Riancho mucha cantidad de pesos de oro y lo sabe este testigo por lo aver oydo dezir a los dichos vezinos por publico e notorio en esta dicha ciudad y no ay duda en ello y esto rresponde desta pregunta.

$/ \mathrm{F}^{\circ} 5 \mathrm{v}^{\circ} / 3$. A la terçera pregunta dixo queste testigo a visto de hordinario quel dicho Gonzalo de Riancho a echo las comedias que se an echo en esta dicha çiudad los dias de Corpus y otras que la çiudad a echo fiestas solenes con su conpañia con mucho ornato, conforme se usa en Castilla y no se an echo tan bien ni tan a gusto como el dicho Gonzalo de Riancho lo haze en esta çiudad y lo mesmo a oydo dezir a otras muchas personas en esta dicha çiudad y esto rresponde a esta pregunta. 
4. A la quarta pregunta dixo que sabe la pregunta como en ella se contiene, por que este testigo a visto la casa quel dicho Francisco de Leon tiene en esta dicha ciudad adonde el dicho Riancho reçita ques la mejor queste testigo a visto en algunas partes despaña por tener como tiene comodidad aparte para las mugeres y los honbres de suerte que no se pueden comunicar los unos ni los otros en lo qual le pareçe a este testigo que abra gastado el dicho Francisco de León la cantidad de pesos de oro que la pregunta dize por la aver echo desde los çimientos para el efeto de que se representase en ella y ser tan buena como es y esto rresponde.

5. A la quinta pregunta dixo queste testigo sabe que conviene que las rrepresentaçiones quel dicho Riancho haze en esta dicha çiudad se hagan e prosigan y se le avia de dar premio por ello al dicho Riancho porque se escusan con ello muchos juegos que se hazian antes que las dichas comedias se rrepresentasen e pecados publicos y cesa todo lo suso dicho con yrse a ver las dichas comedias y le pareçe a este testigo que sería nesçesario que se hiziesen los dias de fiesta y otros de trabajo por lo suso dicho y todo el pueblo e comun gustara dello y es bien della y esto es lo que sabe y la verdad para el juramento que fecho tiene y firmolo de su nombre. Benito Beltran. Paso ante mi: Juan Alonso scriuano real. Testigo. En la çiudad de Mexico a diez y nueve dias del mes de nobienbre de mill y quinientos y noventa y siete años el dicho Gonzalo de Riancho para la dicha ynformaçion presento por testigo a Christoval de Medina procurador de la audiencia hordinaria desta dicha çiudad del qual se rrecibio juramento por Dios Nuestro Señor e por la señal de cruz so cargo del qual prometio de dezir verdad y preguntado por el ynterrogatorio dixo lo siguiente:

1. A la primera pregunta dixo que conosçe al dicho Gonzalo de Riancho y a Francisco de Leon de mas de diez años a esta parte. /Preguntado por las generales de la ley dixo ques de hedad de mas de treynta y çinco años y no le tocan ninguna dellas.

2. A la segunda pregunta dixo que lo que della sabe es que aunque algunas personas hazian comedias en esta dicha çiudad de algunos años a esta parte no heran de consideraçion ni fundamento ni tenian casa propinca para el dicho efecto ni bestuarios y del tienpo que a que conosce al dicho Gonzalo de Riancho que a tratado en el ministerio de hazer comedias en esta dicha çiudad sienpre a visto que las reçitaçiones que a echo an sido en casas diputadas para ello y particularmente una adonde las a echo con mucha desençia y onestidad y con muy buen bestuario a los personajes que en ellas salen y le consta a este testigo que a gastado grande suma e cantidad de pesos de oro hasta ponellas en la perfiçion que oy tienen y esto es notorio y lo que sabe desta pregunta. 
3. A la terçera pregunta dixo que a bisto que del dicho tienpo a esta parte el dicho Gonzalo de Riancho a echo todas las representaçiones que se an fecho los dias del Corpus Christo y sus octabarios al uso de Castilla y ansimismo las fiestas de San Ypolito que haze la çiudad con mucho aplauso y gusto de toda esta çiudad y çiudadanos della y esto responde desta pregunta.

4. A la quarta pregunta dixo que lo conthenido en ella es muy publico e notorio y el dicho Francisco de Leon para el dicho efeto de las representaçiones conpro una casa en mucha comodidad desta çiudad donde hizo un treato y lo tiene oy muy abentajado y repartido donde esten las mugeres de por si y los hombres aparte con mucha conpostura en lo qual le pareçe a este testigo que abra gastado mas de los honze mill pesos conthenidos en la pregunta, porque la cassa es una de las mejores que ay en Castilla por averlas visto este testigo alla y eçede esta a ellas, por la linpieça y conpostura que tiene y la buena horden y traza quel dicho Francisco de Leon dio en los rrepartimientos della, y esto rresponde.

5. A la quinta pregunta dixo que a este testigo le pareçe sin duda ninguna que es muy conbiniente las dichas representaçiones en esta dicha çiudad y que se continuen en ella como se haze en los dias de fiesta y otro entre semana porque dello se sigue mucha utilidad a los vecinos por questando ocupados en ella se quitan de muchos biçios / como son juegos y otros biçios publicos y esto se a visto por yspirençia pues despues que ubo las dichas representaçiones an çesado grande suma de juegos y otros defetos que avia en la rrepublica y ansi se le avia de apremiar al dicho Riancho y dalle buen salario de los propios desta dicha çiudad por que no saliese della pues a ella se les sigue la utilidad dicha y esto es lo que sabe y la verdad para el juramento que fecho tiene en que se afirmo y ratifico y firmolo de su nonbre. Christoval de Medina. Paso ante mi: Juan Alonso scrivano real.

En la çiudad de Mexico a veynte y dos dias del mes de nobienbre de mill quinientos y noventa y siete años ante mi Rodrigo de Çarate y Villegas alcalde en esta corte se leyo esta petiçion.

Gonçalo de Riancho y Francisco de Leon vezinos desta çiudad dezimos que ante vuestra merced tenemos dada ynformaçion de la utilidad y provecho que en esta çiudad se rreçibe de que en ella aya representaçiones como las ay los dias de fiesta y algunos entre semana para con ella ocurrir ante su magestad a pedir lo que nos convenga y para el dicho efecto. A vuestra merced pedimos y suplicamos de su pareçer açerca de lo suso dicho y del bien que en ello se rreçibe toda esta çiudad y pedimos justicia Gonzalo de Riancho Francisco de Leon.

El alcalde mando que se le traygan los autos para los ver y proveher justicia. Juan Perez de Rivera scrivano publico. Parecer del alcalde Ordinario. 
- Señor -

Mas de la ynformaçion que tienen dada Gonçalo de Riancho y Francisco de Leon me consta que de aver thenido los suso dichos la cassa de comedia que rrefiere se a seguido grande utilidad a toda esta republica porque se junta y congrega mucha gente a berlas que por no tener esta çiudad otros entretenimientos de nesçesidad se podian ocupar en juegos y otros biçios los quales se esmerçed que pretenden en Mexico a veynte y dos de nobienbre de mill y quinientos y noventa y siete años. Rodrigo de Çarate y Villegas ante mi Juan Perez de Ribera scrivano publico.

Yo Jhoan Perez de Ribera scrivano del rey nuestro señor e publico de esta çiudad de Mexico fize escrivir e fize mi signo.

(Hay un signo) En testimonio de verdad

Jhoan Perez de Rivera

(Firma y rúbrica)

sin derechos (rúbrica)

Los escrivanos que aqui firmamos nuestros nombres çertificamos y damos fee que Juan Perez de Rivera de quien este recaudo pareçe yr signado y firmado es scrivano de su magestad e publico del numero desta çiudad y los auctos y escrituras que ante él an pasado y pasan se a dado y da entera fee y credito en juicio y fuera del fecho en Mexico a veynte y quatro dias del mes de nobienbre de mil y quinientos y noventa y siete años.

Luis de Leon, scrivano publico.

Jhoan de Vallejo, scrivano de su magestad. Luis Castellano, scrivano publico.

(Firmas y rúbricas)

\section{/AL DORSO:/}

Ymformacion de Gonçalo de Riancho y Francisco de Leon para que puedan representar en la çiudad de Mexico en sus casas. 